\title{
La cruel pedagogía del virus en la educación matemática: un análisis autobiográfico-narrativo
}

Milagros Elena Rodríguez ${ }^{1}$

\section{Información de artículo:}

\section{Recibido: 30/03/2021}

Aprobado: 30/05/2021

Palabras claves:

Transparadigmática, Educación Matemática, narrativa, autobiográfica.

\section{Key Words:}

Transparadigmatic, Mathematical Education, narrative, autobiographical.

\section{Resumen}

En medio de la crisis tradicional de la matemática ahora se le agrega la crisis encuarentenada de dicha ciencia en el uso de las tecnologías y la educación a distancia con las improvisadas prácticas. Se usó la indagación biográfico - narrativo, como una herramienta para la investigación educativa para analizar la cruel pedagogía del virus en la Educación Matemática en tiempos de pandemia comenzada en el año 2020, como objetivo complejo. Concluyéndose en estructuras rizomáticas, que los tres casos narrados en la indagación se requiere en los procesos educativos de la matemática se autoevaluasen los actores del proceso educativo a la luz del hacer ético de lo que significa educar; de la responsabilidad de despertar el amor, pasión y utilidad de la matemática en la vida del discente. En cuarentena es urgente tomarse el encierro para reflexionar responsablemente sobre lo que hacemos en nuestra praxis; ¿Cuáles son nuestras carencias a la luz de tantos resultados de la didáctica de la matemática que están a disponibles de la lectura en la red Internet? Desde donde investigando y concientizándonos pueden devenir salidas a la crisis.

\section{The cruel pedagogy of viruses in mathematical education: an autobiographic-narrative analysis}

\section{Abstract}

In the midst of the traditional crisis of mathematics, now the quarantined crisis of said science is added in the use of technologies and distance education with improvised practices. Biographical-narrative inquiry was used as a tool for educational research to analyze the cruel pedagogy of the virus in Mathematics Education in times of the pandemic that began in 2020, as a complex objective.

\footnotetext{
1 Postdoctora en Enseñanza de la Matemática. Profesora Investigadora de (iD) https://orcid.org/0000-0002-0311-1705
} 
Concluding in rhizomatic structures, that the three cases narrated in the inquiry are required in the educational processes of mathematics, the actors of the educational process self-evaluate in the light of the ethical doing of what it means to educate; of the responsibility of awakening the love, passion and usefulness of mathematics in the life of the learner. In quarantine it is urgent to take confinement to reflect responsibly on what we do in our praxis; What are our shortcomings in the light of so many results of the didactics of mathematics that are available from reading on the Internet? From where investigating and raising awareness can become solutions to the crisis.

\section{Rizoma: sentires, provocaciones, necesidades y la transmetodología de la indagación}

Como lectora de las obras del Sociólogo Boaventura Do Santos, el portugués, brasileiro con corazón complejo que propende la eliminación del pensamiento abismal: el de Occidente y el Sur, el de los saberes científicos y los soterrados; el de los topois, lo separado por el paradigma modernista; de su más reciente libro titulado: la cruel pedagogía del virus y allí rescato una frase muy contundente: "estoy seguro de que en el futuro cercano esta pandemia nos dará más lecciones y que siempre lo hará de manera cruel. Si seremos capaces de aprender es una pregunta por ahora abierta" (Santos, 2020, p.75). De ahí el nombre muy sugestivo de la indagación; con la seguridad que las lecciones que recibimos deben ayudarnos a mejorar.

Quien le escribe, matemático, educadora e innovadora de profesión y corazón, a más de 28 años de experiencia en la Educación Matemática Universitaria, en la que la matemática ha tenido como instrumentos la pizarra, tiza, luego marcadores de pizarras en largas tareas metacognitivas de alto nivel ha sido participe de dichas tareas, las he promovido y he penetrado en los aportes de las tecnologías con las innovaciones, creatividad que han sido apoyos en los ambientes de aprendizaje de la matemática.

Antes de continuar, indico que la narrativa de los hechos ocurre en primera persona, autora con el lector; y que se propenden hechos personales vivenciados en la Educación Matemáticas; esto es porque se está usando en la investigación la indagación biográfico - narrativo, como una herramienta para la investigación educativa para analizar la cruel pedagogía del virus en la Educación Matemática en tiempos de pandemia comenzada en el año 2020, como objetivo complejo.

Por ello, los hechos son narrados con la subjetividad - objetividad de la autora, rememorando los hechos vivenciados en la Educación Matemática, sus desaciertos, aciertos; su crueldad e imposición, tal cual lo titula con Santos (2020). La autora es doliente y denunciante de la situación, las anécdotas que hacen hoy más que nunca muy cruel y desacertado el hecho de enseñar y aprender matemática, aunado a las creencias, rechazo y las grandes estadísticas de desaprobados y abandonos de cursos 
y carreras relacionados con la matemática. Es la autora agente de cambio en muchas líneas de investigación alrededor de la Educación Matemática en reconocidas publicaciones internacionales; que aunado al momento actual le dan una esencia inédita de lo que sigue ocurriendo muchas veces, oscureciendo más la problemática de la Educación Matemática tradicional. En particular la línea de investigación donde se ubica la investigación se titula: transepistemologías de los saberes y transmetodologías transcomplejas los saberes

No pretendo hacer una historia lineal de la situación, en tanto la manera de narrarlo es transparadigmática, más allá de las investigaciones modernistas; por ello, la palabra denotada en la indagación: rizoma, en este "no hay un comienzo real sino en el medio. Allí donde la palabra "génesis" recupera plenamente su valor etimológico de "devenir", sin relación con un origen" (Zourabichvili, 2007, p.95). El discurso rizomático es complejo y no obedece a estructuras fijas estáticas; si complejas entramadas y si puntos fijos; siempre volvemos al problema y seguimos erigiendo narraciones con líneas de salida. Como autora no estoy comprometida con la tradicionalidad colonial, modernista de hacer Educación Matemática.

Vamos a ver en el discurso como la multiplicidad particularidad propia de una representación rizomática, ya que esto implica que no hay un método y menos una vía única, por lo cual no se puede “"descalificar a priori”. Son muy importantes estas referencias sobre el rizoma, ya que estimulan un pensamiento de la multiplicidad, en cuanto rechazo de un punto de origen" (Sicerone, 2017, p.91); de allí que esta libertad que no es libertinaje investigativo en la construcción, no atiende a juicios modernistaspostmodernistas-coloniales, tiene su plena realización en la decolonialidad planetaria; por donde nos pasearemos regresando a los puntos del rizoma; por ejemplo a la crisis de la Educación Matemática hoy; pero no nos quedamos allí, pues vamos a una reconstrucción esperanzadora de la cruel realidad hoy en día.

Es de hacer notar, que la investigación autobiográfica-narrativa es autobiográfica porque la autora en primera persona narra los hechos vividos en la problemática de la Educación Matemática hoy, se inmiscuye en ellos; que "nos lleva a captar ese conocimiento genuino que un sujeto construye desde su experiencia vivida en diversos espacios y tiempos, permitiéndonos comprender la verdadera esencia de la educación" (Ladín \& Sánchez, 2019, p.227). De ahí las salidas, en tanto problemática de la Educación Matemática encuarentenada en los procesos globalizadores de las tecnologías de la información, instrumentación se develan en el sentir y en los hechos.

Es de hacer notar que en la investigación narrativa, "surge una crisis de los modos paradigmáticos establecidos de conocer, donde se replantea el papel del investigador y la necesidad de incluir la subjetividad para comprender la realidad de las personas que narran sus historias" (Moriña, 2017, p. 19). Es así como en medio de la crisis hoy de la Educación Matemática se develan situaciones que traen salidas donde la formación 
del docente y las políticas educativas que deben reevaluarse a la luz de los tiempos de la tierra actual; cuarentenas encierros; y que esos hechos deben ser aprovechados para dar un viraje a la Educación Matemática. Contar con los instrumentos tecnológicos; pero con el adecuado uso como lo que son: instrumentos importantes y esta vez esenciales; pero jamás suficientes y sustituidores de los docentes.

Se declara que la narrativa sólo tienes fines de investigación y mejora del proceso educativo de la matemática; lo hechos contados por la autora no tienen otro matiz ni la mueve situaciones que enloden el respeto y la buen intención a los actores de los hechos; se ahorran detalles, nombres, y algún otro que devele la identidad de los personajes en las narrativas.

\section{Rizoma: la Educación Matemática encuarentenada}

En este rizoma relato mis experiencias en la Educación Matemática hoy alrededor de los casos evidenciados con el uso de las tecnologías, los instrumentos informáticos y la Educación Matemática encuarentenada; en tal sentido la expresión última delata que en los casos narrados la crisis de la enseñanza de la matemática se ha recrudecido. Podría decir que la Educación Matemática hoy ha estado encuarentenada en el ejercicio de autoritarismo del docente, en la colonialidad de las mentes, encuarentenada en la decadente y reduccionista manera de concebir la matemática. En la escaza formación docente de la que he venido dando cuenta en mis indagaciones. Llevo la lucha de abrir puertas y ventanas, salir al mar y disfrutar la briza fresca, en un aire puro; en comparativa a lo que debemos sentir cuando aprendemos verdaderamente matemática: la libertad metacognitiva de pensar, lo poético del sentir en la imaginación y el proceso concreción-abstracción que nos hace emocionar al sentir las pruebas y diversos ejercicios de la matemática.

El concebir y reconstruir lo que sintieron y vivenciaron sus investigadores; el poder vivenciar en números y relaciones la matemática en la vida, en la cultura y cotidianidad; ese proceso reverso, he hay un problema de la realidad, ¿Cómo lo planteo matemáticamente?, ¿Cómo vivencio sus condiciones iniciales? Más aún: ¿en cualquier situación de la vida como puedo discernir la matemática en ello? Es que esos hechos que ante matemáticos lectores son muy evidentes han estado encuarentenados en el aula. Ya sabemos que han sido prohibitivos, exceptos ejemplos de verdaderas pedagogías vivas, hermosas en la vida de los actores del proceso educativo.

Ahora si aunamos a los hechos ya crueles antidemocráticos y prohibitivos de la matemática en la vida de los estudiantes; si súmanos sin exagerar: la aplicación escueta de las tecnologías en la vida encuarentenada por el virus, la exclusión de las tecnologías en muchos casos por la escasez de instrumentación (computadoras, celulares, entre otros), la red de internet decadente o nula, la escaza formación docente en materia de las tecnologías aunada a su decadente pedagogía; entonces la crueldad se magnifica, 
la matemática se esconde en los cajones de su historia y el rechazo aumenta; o nos mentimos en pensar que aprobamos muchos estudiantes, que enseñamos y desde luego aprendieron y que los discentes conocen mucha matemática desde los vicios de copia y pega u otra situación antiética con el uso de las tecnologías.

Narraré hechos encuarentenados relacionados directamente a la Educación Matemática hoy: sin dejar rezagos de personas, nombre o situaciones que develen instituciones; narraré los hechos a la luz de lo ocurrido y mi experiencia, lo haré enmarañadamente; el primer hecho ser facilitadora en un seminario de estudios de postgrado y al mismo tiempo estudiante de dichos estudios en los restantes seminarios; segundo: mi apoyo a un estudiante universitario en un curso de matemática, soporte presencial en medio de su curso online con la universidad donde cursa su carrera; y por último: apoyo tecnológico a un estudiante de Educación Secundaria en Venezuela y su proceso de enseñanza encuarentenada de la matemática.

En el primer hecho ser facilitadora en un seminario de estudios de postgrado y al mismo tiempo estudiante de dichos estudios en los restantes seminarios, se puede decir que en tanto los cursos más allá de los grados de cuarto nivel, en Venezuela, refieran a la enseñanza de la matemática devienen de un análisis de la matemática y sus métodos de enseñanza, estudios que sin contenidos matemáticos pueden ser como charlas de deporte, fuera del campo del ejercicio de dicho deporte. O sea, si yo soy deportista puedo deconstruir los procesos de cómo se lleva el deporte, hacer propuestas e ir a su epistemología; pero debo inmiscuirme en determinadas técnicas, ejercicios y el cómo se realizan; con ello epistemología del deporte y epistemología de la enseñanza del deporte están íntimamente relacionado. Así, la comparabilidad de esta sátira discursiva lleva a que no hay posibilidad de estudios de la enseñanza de la matemática sin la matemática; sin el calor de sus contenidos, de sus ejercicios; si hay propuestas esta va dirigidas y afectan a los contenidos y no sólo como estos se presentan. Y si se quieren llevar de manera diferente estos contenidos deben aparecer en el proceso.

Podemos tener seminarios de estudios de postgrados relativos a los métodos e historia de ellos, o de algunas categorías que propendemos inmersionar en las nuevas propuestas de cómo hacer matemática bajo paradigmas o transparadigmas; pero en el momento de inmersiona en la geometría, aritmética, álgebra las ecuaciones aparecen, los gráficos se dibujan, y cuando las tecnologías aparecen entonces los paquetes computacionales hacen su escena de aportes. No es fácil definir quién es el centro de los hechos educativos en dichos estudios; lo sí es cierto en todo lugar y tiempo que no hay Educación Matemática sin matemática.

Así mismo, se confunde y minimiza el papel del denominado: facilitador, docente, maestro, profesor; en cualquier caso debe en realidad facilitar siendo el ejemplo de lo que solicita hacer ante los estudiantes que en este caso profesionales dirige; en medios 
online pareciera que la tarea del educador se anula en tanto la sociedad globalizadora de las tecnologías de la información educan. Esto es un grave error. En mi entender los medios encuarentenados de las tecnologías facilitan en tanto la distancia física es inevitable; pero esos medios siguen siendo instrumentos no los que sustituyen el papel del educador. Desde luego, bien guiados los medios tecnológicos se convierten en ayudas idóneas del educador-educando, educando-educador. ¿Por qué las diadas?

Respondo a la pregunta anterior, por qué teniendo el docente la claridad que está aprendiendo en medio del proceso pues reconoce su insuficiencia, él se convierte en educando; y estando en acuerdo el estudiante aprende y enseña al docente, en tanto este lo permita; por ejemplo los discentes de esta era con los medios tecnológicos son más agiles, y el docente debe estar dispuesto a aprender. En mi narrativa declaro insólito facilitar un seminario de historia de la matemática, cuando no se narra un solo hecho de la creación de algún aspecto, o concepto de la matemática que es tan valioso; cuando el facilitador se concentró a asignar algunas tareas donde todo vale en medio del proceso de facilitación.

Se pierde un momento precioso para mostrar como desde la historia de la matemática se educa; en un mes de duración del seminario la imaginación vuela con las diversas actividades que sin desmitificar la intencionalidad se pueden hacer. Además debemos estar consciente que como docentes, cuando asignamos algunas tareas y ellas no se comparten o debaten entre los educandos queda fuera el proceso de retroalimentación de aprendizaje que bien podía alimentar el proceso.

Se acostumbra a desmitificar los hechos en tanto son profesionales ya egresados de las universidades los que desde luego realizan los cursos de postgrados. Ahora, ¿son los estudios de postgrados para mejorar la formación del profesional a fin de promover directa o indirectamente el progreso, en este caso, de la enseñanza de la matemática? Son reflexiones a realizar. Esos egresados facilitarán seminarios en cortes futuras, se espera que ellos aporten al proceso en tanto aprendieron en sus propios estudios. Se desmitifico el estudio de postgrado que les narro.

Por otro lado, siendo la antropoética, la ética del genero humano, una categoría promovida en dicho estudio de Postgrado, la evidencia en tanto copia y pega de las diversas fuentes de internet se hizo palpable, donde se justificó que eso se podía hacer sin citar la fuente porque no se trataba de publicaciones arbitradas, sino opiniones en los medios tecnológicos de uso del estudio. ¿No es la realización de la cita a la fuente de autor, en cualquier momento de nuestras vidas, la norma ética?, creo que devela una carencia ética grave que trae consecuencias, y la ha venido trayendo en el paso de las personas que cometen dichos delitos, en sus funciones como profesionales. Esta narrativa no es un suceso de culpas, de víctimas, o no. Es un llamado de atención a que la Educación Matemática ahora encuarentenada no puede ser un ejercicio banal, 
cargado de vicios. Los docentes somos convocado a aportar lo mejor de sí, en medio de la metamorfosis; de la cruel realidad vivenciada en la cuerentena.

Para culminar esta narrativa en el primer caso, en el curso de postgrado, que representaba buscar salidas a la problemática en la educación secundaria por ejemplo en Venezuela, les narró que incite proponiendo ejemplos elementales de cálculo para en los foros de por ejemplo geometría o algebra se resolvieran de manera amena, con nuevas propuestas; aprovechando seguramente las tecnologías u otras propuestas. La respuestas en el 90\% de los cursantes fue de molestia en tanto aludían que el motivo no era discutir procesos de resolución de problemas de matemáticas en el mismo seminario denominado: resolución de problemas. Son hechos insólitos en donde se deconstruye la resolución de problemas de matemática sin hablar o tratar alguno en particular.

Por otro lado, ¿cómo se gestiona la matemática en el caso que narro del estudiante universitario? Creo que en este caso el exceso de conocer la tecnología deja en evidencia que el docente desmitifica su papel en este caso; el remate de tiempo de temas que en áreas presenciales usando tecnologías es realmente preocupante. En tanto el estudiante desconoce en un curso de cálculo en el segundo semestre excluye la aritmética elemental; y continua en ello en ese desconocimiento; sacar mínimos cuadrados, dibujar una parábola fue una imposibilidad en el estudiante al tiempo que hacerlo con Desmos, y otros paquetes computacionales lo sabe hacer; pero el proceso metacognitivo lo pierde en el desarrollo del cálculo.

Al mismo tiempo el docente remató contenidos o temas como áreas, volúmenes en una sóla conferencia, presentando unas láminas en el procesado Power Point con ejercicios resumidos extremadamente en su proceso de solución; donde el proceso intrincado de resolución a distancia se encuarentena; se encerró en lo que no se dice; un maquillaje de los procedimientos; en un cálculo asignatura que luego será evaluada en los exámenes de mayor peso, o porcentaje de evaluación con ejercicios con procesos muy extensos como sabemos son los de volúmenes y áreas y los teoremas intrínsecos a ello. Muy mal orientación la del docente; en tanto el cálculo manual debe ser un ejercicio que ejecute y enseñe como hacerlo al estudiante, y este corroboré resultados con paquetes computacionales, en sus gráficas cálculos u otros.

Si el proceso del cálculo es esencial, en el desarrollo metacognitivo del estudiante, comprendiendo, emocionándose, comprobando con ello el ascenso y desarrollo de nuestra compleja inteligencia; aunado a que será evaluado en el curso; ¿por qué ese proceso se obvia y se privilegia a cambio el resumen de los problemas, y luego la misma tecnología que el estudiante puede usar no es la que se usa en largos procesos en una evaluación? ¿Dónde queda el papel de orientador del docente, de despertar el amor por la ciencia legado de la humanidad: la matemática? ¿Con las tecnologías se encuarentena también el proceso orientador, emotivo, asertivo; la enseñanza de 
la matemática con mente, cuerpo y corazón? En este caso que narro sí ocurrieron tales hechos.

En el caso del segundo parcial él estudiante en largos procesos de calculo que no domina que debe hacer paso a paso, pero que no le enseñaron hacerlo en detalle, sino que usa los paquetes computacionales; en ese proceso se equivocó en colocar el resultado del límite superior de una suma admitiendo una igualdad; pero en el proceso lo hizo correctamente; luego usa dicho valor correctamente en la segunda parte del problema y hace otro calculo correctamente; por la prisa el estudiante no le da tiempo revisar; en una evaluación de tres (3) horas, y el docente le resta los tres (3) puntos en dicho problema; en el reclamo el estudiante no gana su reclamo; el docente alude que el estudiante copio el problema; pero como se copia un hecho tan original en la solución de problemas; es que en el uso de las tecnologías con este tipo de evaluaciones el docente no puede comprobar si se copia el estudiante; pero tampoco puede pensar que ante un pequeño error de transcripción el estudiante se copió. Son hechos graves en la enseñanza de la matemática en épocas de pandemia.

Sin duda, al revisar el examen, segundo parcial mencionado, sin duda su solución para ser ejecutada por un estudiante muy aventajado necesitaría más de tres (3) horas para su solución. ¿Cuánto tiempo, vía online debió dar la docente para resolver un examen con muchos cálculos, exigiendo que los cálculos se muestren en detalles, incluyendo en envío en medio del caos de internet en Venezuela? ¿Cómo minimizar el copiarse, presentando evaluaciones vía online en sus estudiantes? Más aún, ¿Cómo asegurarse que el estudiante esta dominando los cálculos, los temas? Sin duda, presenciando vía online la ejecución de la solución de algunos problemas por parte de sus estudiantes, el aprendizaje colaborativo en la que los compañeros puedan irse ayudando, donde el docente pueda estar alerta a las dificultades y carencias de sus estudiantes. Ello, no es un proceso sencillo; pero debe ser contactado.

Un hecho notorio es que con los paquetes computacionales; si ellos son el centro de la enseñanza de la matemática en temas de cálculo inicial; si estos temas no se enseñan cómo se hacen en su esencia, de acuerdo a su definición puede llegar el caso, y en el caso que narro ocurrió que el estudiante maneja adecuadamente una calculadora sabe colocar una fracción por ejemplo, pero no sabe clarificar porque 2/3 es un valor menor que uno, pierde así la esencia de lo que es una fracción; llega a saber cuál es el resultado de la suma de una fracción; maneja muy bien la calculadora, pero no sabe sacar mínimos cuadrados. Mucho menos cuando tuvo que integrar en un largo proceso puede tener el resultado con las tecnologías; pero no conoce el procedimiento que luego le pedirán; peor aún algunas integrales que por las indeterminaciones las calculadoras o paquetes computacionales no hacen.

En el caso por ejemplo de Desmos, una calculadora gráfica, el estudiante en la narrativa, sabe manejar muy bien el colocar las funciones y graficarlas para ver el área 
que va a rotar para el cálculo de un volumen; en el caso que les narro; por ejemplo: La base de un sólido es la región limitada por la curva $\bigotimes$ = y su asíntota la cual es el eje $\mathrm{x}$, si $₫ \geq 0$. Las secciones perpendiculares al eje x son rectángulos cuya altura está representada por la función. Calcular el volumen del sólido. ¿Qué realizó el estudiante de la narrativa con Desmos para ayudarse con el problema? Gráfico las funciones sin problema y obtuvo:

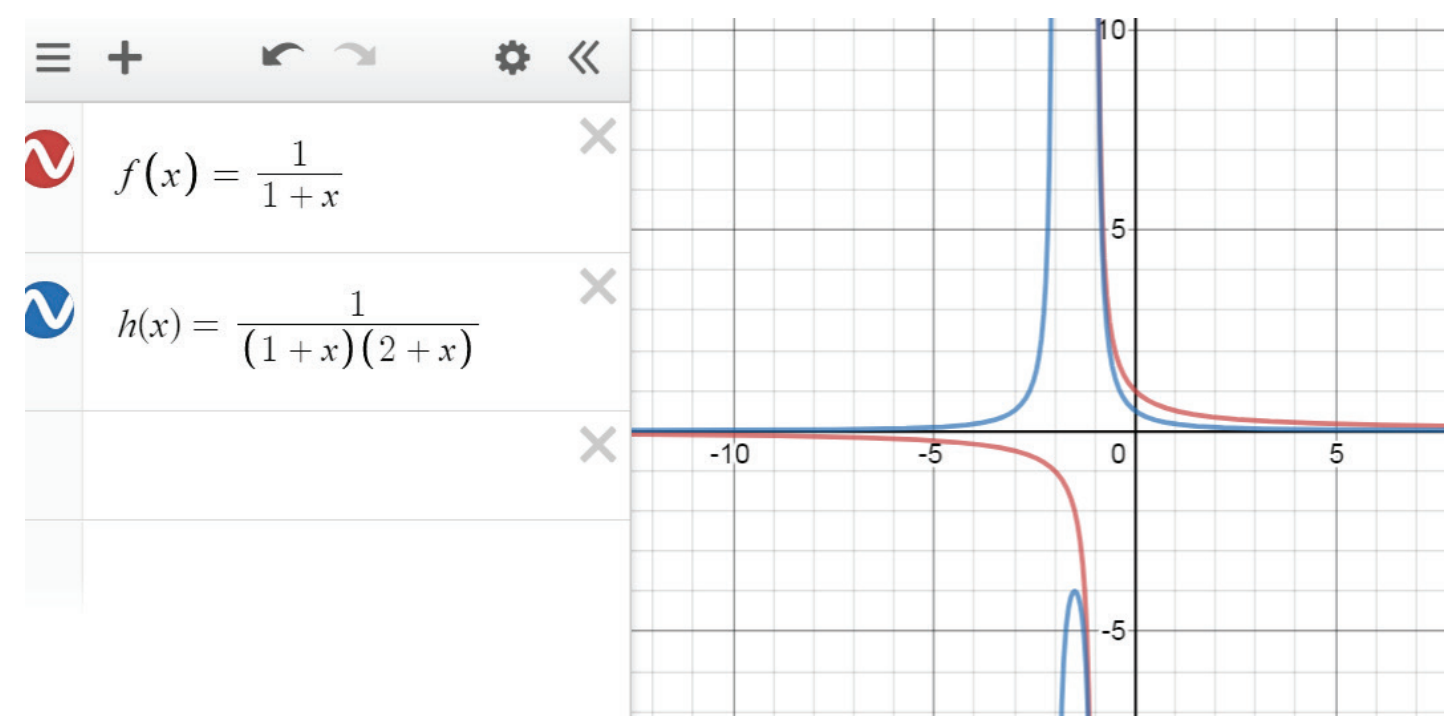

Figura 1: Realizada para la investigación 2021.

Ahora con las gráficas, en las que las realizó sin tener en cuenta por ejemplos las asíntotas de las funciones, detrás de ello hay interrogantes que ahora debió develar para el cálculo del volumen del sólido: ¿Cuáles son las secciones perpendiculares al eje $\mathrm{x}$, rectángulos con alturas la función $\mathrm{h}(\mathrm{x})$ ? ¿Qué formulas usará para el cálculo de volumen? Evidentemente con ello quedo cuesta arriba la solución del problema.

En la narrativa de los hechos a los que me refiero, desde luego se obvian muchas dificultades presenciadas en el caso del estudiante universitario. En tanto la excesiva cantidad de temas que el docente quiso enseñar con tres conferencias a sus estudiantes son viajes imaginativos del docente que distan del verdadero aprendizaje de su estudiante, pretender que una evaluación parcial en este caso con temas tan extensos al detalle como: aplicaciones de la integral definida, volúmenes de sólidos con secciones transversales semejantes, centro geométrico, Teoremas de Pappus, sucesiones y series, incluyendo series de Taylor y Maclaurin. Todo ello es una aberración e irrespeto como evaluación parcial a su estudiante; en medio de los ensayos con la educación a distancia. Es un desgaste y muy poca probabilidad aprobar la materia de cálculo; pero lo peor una posibilidad muy mínima de que dicho estudiante aprenda temas tan esenciales de matemática. Desde luego, más adelante tenemos rizomas mesetas de 
liberación de la matemática encuarentenada en la educación hoy donde explicitamos algunas recomendaciones.

En el tercer caso, el joven estudiante en el curso de matemática de la Educación Secundaría en pleno ardor en estos momentos en Venezuela. También ocurren hechos en la cruel pedagogía de la Educación Matemática. Se trata de un joven adolescente, una etapa en la que sabemos las dificultades que por su edad todo joven, dependiendo el medio, la familia, las instituciones educativas, son procesos de adaptación. El joven es aventajado en las tecnologías, un ser humano accesible y cariñoso; más conocido por mi persona por pertenecer a mi familia. En su curso de matemática la docencia online se dio con unas guías que se entregaban y ejercicios online, en su mayoría, con pruebas de selección, en un tiempo dado; en el que el joven podía preguntar con sus compañeros cuanto era el resultado y podía responder sin tener conocimiento del contenido matemático.

Especial atención ocurrió, pues al ingresar a esa institución por traslado de otra le falto presentar los dos primeros exámenes; entonces al final el docente lo invita presencialmente a presenta ese examen con todos los casos de potenciación, radicación y el método de raíz cuadrada exacta con varios dígitos; lo hace el docente de un día para otro; eso crea una presión en él estudiante. Debido a ello, al solicitarme ayuda como docente estuve varias horas intentando enseñar al estudiante vía online los diversos casos de tales temas, existió la imposibilidad de vernos por la cuarentena en nuestro país; un ejercicio titánico para el tiempo. Afortunadamente el estudiante aprobó el examen presencial escrito. Pudo hacerlo, pese a que fue el único examen presencial; y no obtuvo la máxima nota.

Es de hacer notar que en los exámenes online dicho estudiante no pudo mostrar el dominio de esos temas de matemática; y además la posibilidad de copiarse es mucha; el docente pudo estudiar estrategias más certeras para indagar en cada estudiante su proceso de aprendizaje; que pudo ser más tiempo que en el caso presencial; si disponía de la red de internet; cuestión muy caótica en Venezuela.

Las consecuencias se ven a largo plazo, en tanto sabemos que los contenidos de matemática son estilo escalera; de un escalón en otro escalón, paso a paso; sino sabes por ejemplo, extraer mínimo común denominador es difícil que sumes o restes fracciones correctamente; sino dominas derivadas, límites, como el caso del segundo caso narrado no puedes integrar correctamente; como en efecto ocurrió. Sabemos las dificultades en pandemia, las tecnologías llegaron hace tiempo; hoy ocupan un lugar especial; pero el docente debe renovarse en su uso y las políticas educativas en tal materia deben incentivarse y dotarse de los recursos necesarios.

Especialmente en la enseñanza de la matemática debe combinarse en el análisis manual y el apoyo de las tecnologías; las evaluaciones son de delicado cuidado vía 
online; es un tema que esta virgen el análisis. En lo que deviene algunas mesetas de liberación de la matemática encuarentenada en la educación hoy. Es de comprender que hay detalles de los casos narrados que no se cuentan para no violar la confidencialidad e identificación de los docentes y de los estudiantes involucrados. Como matemático sé que estos casos no son únicos y las conversaciones de familiares y amigos vía redes sociales, telefónicas son muchas en las carencias de la Educación Matemática encuarentenada. Por ejemplo, un tema a estudiar es el papel de la familia en ello.

\section{Rizoma mesetas de liberación de la matemática encuarentenada en la educación hoy}

En este rizoma, vamos a proponer mesetas de liberación de la Educación Matemática encuarentenada de la educación hoy; como señala Rodríguez (2021) sabemos que "no es fácil los cambios que la resistencia se opone siempre la cambio, es más esa es la resistencia, que el desaliento, la desmotivación la falta de fe reguladora del amor de Dios presente en nuestros corazones es urgente" (Rodríguez, 2021, p.18). La Educación Matemática puede enseñar el amor, el potencial, puede enseñar a conocer nuestra condición humana; para ello el docente debe pasar por el filo de la reforma del pensamiento para que pueda enseñar lo que ha podido experimentar; así en plena pandemia, los procesos de enseñanza online. "El cambio de pensamiento, la reforma del pensar es un deber ético que tenemos con nosotros mismos, no nacimos acabados, nuestra infinitud del potencial del cerebro lo dice" (Rodríguez, 2021a, p.18).

En tal caso en mi narrativa, los diferentes casos, es urgente en general la debida vigilancia epistemológica de los contenidos de la matemática en nuestros estudiantes; más aún en época de pandemia; en que los medios tecnológicos son instrumentos, aun cuando llegaron hace un tiempo, son medios de muchas aristas a vigilar y desmitificar; bien aprovechados son sumamente potentes para enseñar, crear ambientes de aprendizaje, comunicación sincrónica y asincrónica, medios potentes de graficación, animación. Comunicación del grupo en general de los actores del proceso educativo.

En Venezuela, en particular la incorporación de medios de enseñanza conocidos como percepciones directas con las tecnologías, medios destruidos y mal usados por las faltas de políticas formativas y de supervisión, útiles para lograr una mejor enseñanza en las aulas de clases; es urgente abrir espacios para que los discentes puedan crear nuevos aprendizajes desde sus propias experiencias y ubicarlos en el contexto social donde se desenvuelven (Rodríguez, 2020a).

Es importante clarificar este ejemplo que muestra la relación entre límites y la intuición con la gráfica; aprovechando la tecnología; por ejemplo con el paquete computacional Desmos; si quisiéramos calcular en caso de existir el límite de la función $\mathrm{f}(\mathrm{x})=1 / \mathrm{x}$ cuando $\mathrm{x}$ se acerca al valor de cero (o) realizando la gráfica con del paquete computacional mencionado; que verifica la asíntota en $\mathrm{x}=0$; donde sabemos que la 
$\mathrm{f}$ tendrá dos ramas; una para $\mathrm{x}$ menores que cero donde sus imágenes son negativas y otra donde $\mathrm{x}$ es mayor que cero y sus imágenes son positivas (Rodríguez, 202ob). Teniendo la gráfica de dicha función $\mathrm{f}(\mathrm{x})$ :

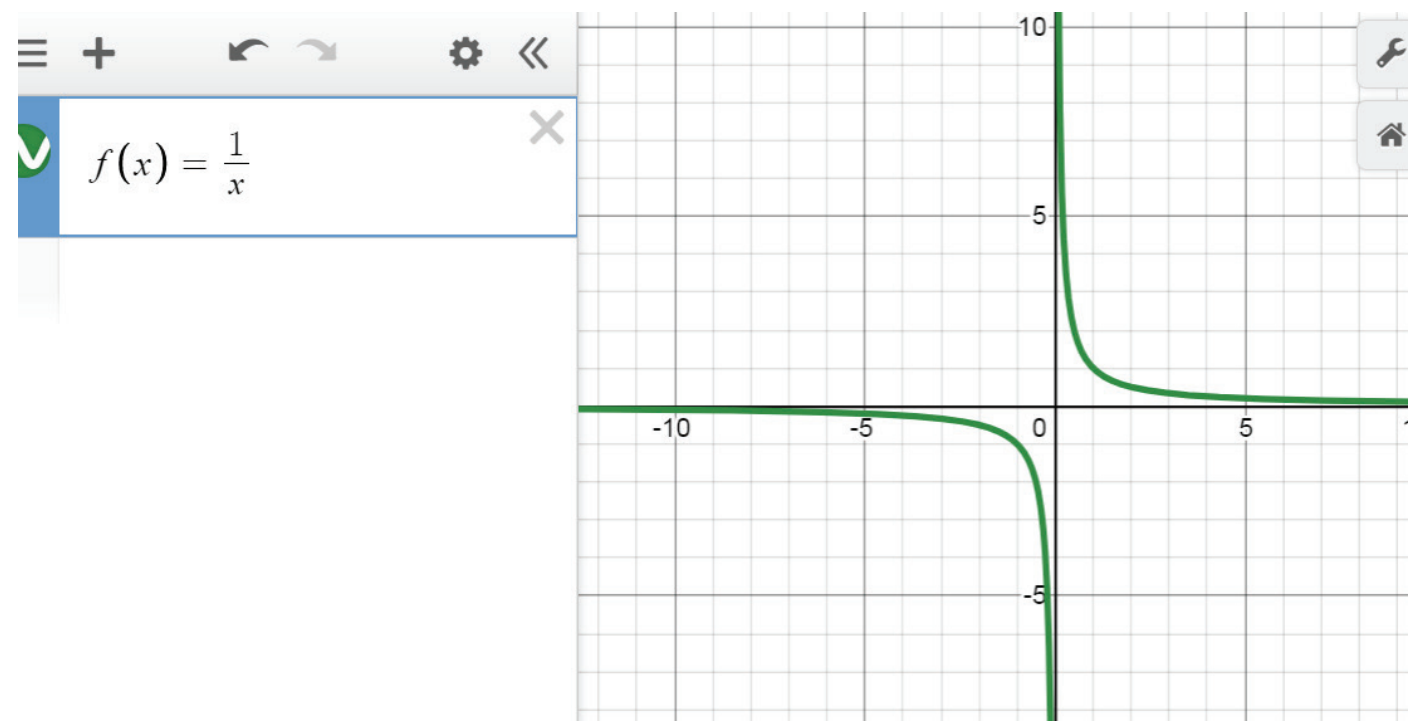

Figura 2: Realizada para la investigación 2021.

Veamos qué, que cuando $\mathrm{x}$ se acerca al valor cero (o) por la izquierda (valores negativos) la función $\mathrm{f}$ decrece indefinidamente; por el contrario cuando $\mathrm{x}$ se acerca a cero por la derecha (valores positivos) la función $\mathrm{f}$ crece indefinidamente. De allí, el límite propuesto inicialmente de $\mathrm{f}(\mathrm{x})=1 / \mathrm{x}$ cuando $\mathrm{x}$ tiende a cero no existe. La gráfica, la intuición es indispensable; y combinada con la tecnología, con el paquete computacional denominado Desmos en este caso; pero pudo ser con GeoGebra; que en la red de Internet hay muchas versiones gratuitas (Rodríguez, 2020b). Se puede incentivar un poco más, explorando al geómetra, imaginando posibilidades, ¿Cómo calculamos el área bajo la curva de $\mathrm{f}(\mathrm{x})$ con los ejes cartesianos?, ¿influye el hecho que la función no está definida en en $\mathrm{x}=\mathrm{o}$ en el cálculo de la integral?, bajo el eje de simetría de la gráfica ¿qué debemos de hacer para el cálculo del área?

Los instrumentos tecnológicos poseen apoyos importantes en tanto el apoyo clarificado del docente se dé. Para ello, en línea el estudiante puede usar las herramientas y ser interrogado y debatido en un aprendizaje colaborativo para llegar al aprendizaje. Si ya enseñar matemática de manera presencial por las diferentes dificultades que se han venido estudiando; menos podrá haber un aprendizaje si las clases online son rematadas por grandes cantidad de ejercicios en que el estudiante no llega al aprendizaje. Con los medios tecnológicos podemos motivar captar la atención de los estudiantes y para hacerlos mejorar la comprensión de los conceptos matemáticos, la emoción en la imaginación; la comprobación de que lo que hacemos en algunos casos 
se pueden realizar con ayudas de paquetes computacionales; el ver las limitaciones de dichos paquetes.

En cuanto a la evaluación de los aprendizajes de los conceptos matemáticos online, encuarentenados debe ser cuidadoso evitando el plagio; para ello la solución no puede ser implementar evaluaciones con grandes cantidades de cálculos de imposible realización en el tiempo asignado. Se deben crear actividades evaluativas en las que el estudiante sea interrogado y el docente pueda retroalimentar y reevaluar a la luz de nuevas explicaciones. Pero los procesos de retroalimentación no se pueden dar de la misma manera como se explicó inicialmente; se deben renovar las técnicas, las instrumentaciones. La diversidad de paquetes, páginas web, y todo el apoyo debe ser usado adecuadamente.

El docente de matemática no puede eludir los conocimientos previos necesarios para comprender y hacer los cálculos adecuados. La interrogación es esencial para ello, los porque; la indagación personalizada estudiante a estudiante puede hacerse de manera amena; animando, haciendo llegar al conocimiento ascendiendo desde el error; el error no puede ser castigado con el látigo encuarentenados del silencio, o el castigo de la mínima puntuación. En un ejercicio por ejemplo de límites indeterminados, en la que la indeterminación se puede eliminar factorizando el docente en sus clases debe contactar el dominio de los diferentes casos de factorización por sus estudiantes; ello no es imposible hacerlo antes de la evaluación vía online: ¿Cuál es el caso más elemental de factorización? Desde luego que el factor común. En un ejercicio de este tipo el docente puede contactar si se ha factorizando correctamente y se evaluó mal luego. Todo ello debe ser contactado. La misma clase colaborativa en el docente de matemática se debe convertir en un proceso de evaluación. ¿Qué hay de su autoevaluación como docente? Urge un cambio desde la aceptación de nuestras carencias.

En plena cuarentena, con juegos online, como el Tangram podemos despertar el amor en nuestros discentes por la geometría; pero para ello se deben reconocer las figuras en tanto sus lados, ángulos; el desarrollo del pensamiento profundo con la lógica-matemática se puede desde estrategias complejas, como: relacionar y clasificar objetos que rodean la vida del discente; elaborar nociones de espacio y tiempo, la formas geométricas (Barragan, Jaque \& Acosta, 2018), número, estructuras lógicas, cuya adquisición es indispensable para el desarrollo de la inteligencia; promover en el niño la experimentación; desarrollar el gusto por una actividad del pensamiento desde la lógica dialéctica, entre otras actividades que despierten el deseo por pensar profundo (Rodríguez, 2020b).

Imágenes de Tangram que se pueden formar, aun cuando no es objetivo de la investigación se invita a apasionarse por el mundo de este apasionante juego se muestran en Rodríguez (2020b), la matemática desarrollando el pensamiento, vía online es posible pasar de lo concreto a lo abstracto y viceversa, pasar de la teoría al 
ejemplo, de lo macro a lo micro; entre otros. El dialogo es esencial en todo momento, vía online se puede realizar, si no establece el diálogo con el discente se puede dar la sumisión, sino ocurre un verdadero diálogo ocurrirán falseadas interpretaciones que el discente mostrará en ese inerte instrumento tecnológico donde le es evaluado su memoria, más jamás su inteligencia, su creatividad (Rodríguez, 2020b).

Sabemos los grandes males de la pandemia 2020; los efectos de la cuarentena los padecemos a la luz de las injustas políticas educativas implementadas en Venezuela aunado al grave problema de la situación país; de ahí que muchos docentes somos guerreros en medio de la oscuridad. Sabemos que la etapa postpandemia traerá serios cambios a la humanidad. En la Educación Matemática, en medio del desierto queremos aprovechar para que se den cambios que hace tiempo se vienen proponiendo; pero que las falsas política educativas aunado a la formación y resistencia del docente no han sido posibles; en pocos casos sí; en muchos otros paliativos; pero el problema de vieja data de la Educación Matemática ahora en cuarentena se ha rasgado las vestiduras y se ha mostrado la crudeza.

Es urgente, aun en cuarentena el re-ligando emerge, el gran espectro del pensar profundo que provee hacer matemática; se trata de tener un pensamiento complejo (Rodríguez, 202ob). Propuestas que están al ardor de la investigación de la autora, en dicha donde se ubica la investigación: transepistemologías de los saberes y transmetodologías transcomplejas los saberes: y en la titulada: Educación Matemática Decolonial Transcompleja; donde urge mostrar que la matemática no es sólo cantidad, sino cualidad, critica, pensar profundo en un hacer del pensamiento que no debe disolverse o remitirse a un algoritmo; ellos son sólo herramientas no el centro y el hacer de la matemática; la investigación transdisciplinar crítica que se propende como manera de hacer matemática, y que nuestros estudiantes pueden hacer es complementaria, donde los enfoques sean cualitativos-cuantitativos-socio-críticos, y plurales, pues en las fronteras de los conocimientos consiguen esencias complejizadoras (Rodríguez, 2020b).

Los tres casos narrados en la indagación se requiere que fueran narrados por los docentes que participaron en los procesos educativos de la matemática en ese caso; que ellos se autoevaluasen a la luz del hacer ético de lo que significa educar; de la responsabilidad de despertar el amor, pasión y utilidad de la matemática en la vida del discente. En cuarentena es urgente tomarse el encierro para reflexionar responsablemente sobre lo que hacemos en nuestra praxis; ¿Cuáles son nuestras carencias a la luz de tantos resultados de la didáctica de la matemática que están a disponibles de la lectura en la red Internet?

Las tecnologías no pueden ser usadas por el docente, por los actores del proceso educativo para encerrar aún más la matemática, para apartarla y dejarla fuera de las personas, creadores de la matemática, actividades humanas reservadas sólo a unos 
pocos. El docente no puede encarcelar mucho más la matemática bajo la excusa que no es de la época de los medios tecnológicos que no los conoce, pues junto a ellos hay cantidad de manuales, instrucciones y maneras de aprender. Debe aprovechar la soltura y habilidades de sus estudiantes con las tecnologías; pero ello no puede ser para ceder ante que lo más elemental de la matemática no sea conocido y dejado a la responsabilidad de los paquetes computacionales, calculadoras.

\section{Rizoma conclusivo, en medio de la narrativa y la Educación Matemática}

En primer lugar, la investigación transparadigmática, rizomática autobiográficanarrativa devela situaciones que contadas bajo el paradigma modernista es imposible; allí se regula al sujeto investigador con sus experiencias y subjetividades. Los tres casos narrados corroboran una Educación Matemática encuarentenada en la cruel pedagogía del virus en época de pandemia. Las tecnologías en Venezuela están en crisis: de las políticas improvisadas, de la carencia de recursos, de la falta de formación docente y de la crisis de las comunicaciones: un Internet en constantes fallas; aunadas a las fallas constantes de electricidad. Todo ello no lo podemos obviar ante los esfuerzos por continuar con la educación.

La Educación Matemática ha sido encuarentenada aún más, en las mentes de quienes dominan sus conceptos. Los estudiantes que tienen la oportunidad del uso de las tecnologías se encuentran, como los casos narrados en desorientación. Por otro lado, la excusa de la no formación para afrontar el momento actual debe llevar a promover un dialogo ineluctable entre matemática y complejidad, y una necesidad: ¡yo sólo sé que no se nada! (Rodríguez, 202ob). El acto de concientización de sacar lo mejor de sí, e ir a la búsqueda de las soluciones. Se propende la aceptación de que "los saberes matemáticos entre sujetos es intersubjetiva; se rompe el cerco incluso en las construcciones matemáticas de la objetividad determinada del científico (Rodríguez, 2020c, p.86).

Las tecnologías pueden propender bien llevadas, a una instrumentación apoyada en las metodologías innovadoras y creadoras para una enseñanza viva de la matemática, con mente, cuerpo y corazón; animando como el geómetra; en una atención personalizada en medio de la distancia a los discentes; a sus motivaciones y sufrimientos; a su rechazo; pero también a su gusto por los instrumentos tecnológicos. El uso de la cotidianidad y cultura puede ser de gran utilidad; en momentos amenos de ascensión a procesos metacognitivos profundos.

El dejar desquiciadamente el fin, la solución y atender el proceso; como los dicentes en medio de los errores van ascendiendo al conocer los conceptos. Las redes están llenas de vídeos sobre historia y filosofía de la matemática; de programas y paquetes 
computacionales que conjugados con los cálculos manuales pueden dar claridad en los conceptos de la matemática.

En el asunto tan urgente como es la evaluación por medios online, el docente debe evaluarse a la luz de los tiempos y complicaciones para resolver problemas con grandes cálculos cuando ellos han sido rematados en presentaciones obviando la esencia del cálculo, los detalles, las factorizaciones, los mínimos cuadrados, los gráficos. El ejercicio ecosófico-antropoético en ello es motivo de varias investigaciones a la luz de las líneas de investigaciones mencionadas. La autoevaluación debe ser sincera, ateniente a mejorar la práctica; a discernir sobre nuestras carencias; a atender la condición humana del discente. No hay procesos didácticos exitosos si no se confronta con sus evaluaciones constantes; no sólo a la luz de una nota en una evaluación; sino a la luz del rechazo o gusto por ello.

Es notorio que si esta narrativa las hace los docentes en cada uno de los casos la luz que alumbra a las soluciones puede ser mediada por una enseñanza a la luz del aula mente social; el espacio de aprendizaje en todo momento y lugar, mental profundamente complejo y transdisciplinar; que va en estudios en las ya descritas líneas de investigaciones. Pero la narrativa de los discentes, en primera persona puede ser aún más esclarecedora. Siempre debe ser atendido todas estas situaciones a la luz de hacer llegar la matemática ciencia legado de la humanidad en la vida de las personas de manera amena y exitosa.

\section{Agradecimientos y dedicatoria}

En el amor de Dios, el sujeto autora preeminente en la indagación derecho que le da la investigación autobiográfica-narrativa en una liberación onto-epistemológica me despido con la palabra de Dios, mi magnífico creador, matemático por excelencia, les digo "toda la Escritura es inspirada por Dios, y útil para enseñar, para redargüir, para corregir, para instruir en justicia, a fin de que el hombre de Dios sea perfecto, enteramente preparado para toda buena obra" (2 Timoteo 3:16-17). Y él dijo: "antes bienaventurados los que oyen la palabra de Dios, y la guardan” (Lucas 11:28).

\section{Lista de referencia}

Landín M. \& Sánchez, S. (2019). El método biográfico-narrativo. Una herramienta para la investigación educativa. Educación, XXVIII (54), 227-242. DOI https://doi. org/10.1880o/educacion.201901.011

Moriña, A. (2017). Investigar con historias de vida. Metodología biográfica narrativa. Madrid: Narcea. 
Rodríguez, M. E. (2020a). Las investigaciones transparadigmáticas en la Educación Matemática Decolonial Transcompleja. Educ. Matem. Pesq., 22(3), 698-725. DOI http://dx.doi.org/10.23925/1983-3156.2020v22i3p698-725

Rodríguez, M. E. (2020b). Un dialogo ineluctable: matemática-complejidad, y una necesidad: ¡yo sólo sé que no se nada! DIÁLOGO, 45, 43-55. DOI http://dx.doi. org/10.18316/dialogo.voi45.7567

Rodríguez, M. E. (2020c). El pensamiento complejo como propedéutico para la transgestión de los saberes matemáticos. Revista Electrónica de Conocimientos, Saberes y Prácticas, 3(1), 72-89. DOI: https://doi.org/10.5377/recsp.v3i1.9792

Rodríguez, M. E. (2021a). La halterofilia del cerebro como esencia del re-ligar del pensamiento en la educación. Rev. Int. de Form. de Professores (RIFP), 6, e021003, 1-22.

Rodríguez, M. E. (2021b). La matemática en la metacognición o la metacognición en la matemática: metacognición - complejidad - matemática. ReBECEM, 4(4), 539-565. DOI: https://doi.org/10.33238/ReBECEM.2020.v.4.n.4.24986

Santos, B. (2020). La cruel pedagogía del virus. Ciudad Autónoma de Buenos Aires: CLACSO.

Sicerone, D. (2017). Rizoma, Epistemología Anarquista e Inmanencia en la filosofía de Deleuze y Guattari. Revista de Filosofía, 87, 83-94.

Zourabichvili, F. (2007). El vocabulario Deleuze. Buenos Aires: Ediciones Atuel. 